\title{
Dabigatran and statins: faith, hype, and transparency
}

\author{
Trevor Jackson deputy editor, The BMJ
}

This week we put the spotlight on two drug blockbusters at the heart of one of the major issues The BMJ has campaigned on in recent years: transparency, the focus of our Open Data campaign and an issue of vital importance if modern medicine is to retain the trust of doctors and the public. In the case of dabigatran and statins there has been too much emphasis on faith and hype and not enough on transparency. While The BMJ acknowledges the drugs' therapeutic value, the histories of dabigatran and statins are tales of incomplete evidence, in which people are being expected to take too much on trust.

Dabigatran was the first of the new oral anticoagulants licensed to prevent stroke in patients with non-valvular atrial fibrillation. It was approved by the US Food and Drug Administration in 2010 and by the European Medicines Agency for this use a year later. The drug's unique selling point, said its manufacturer, Boehringer Ingelheim, was that it would need no monitoring, unlike warfarin. Once on the market, dabigatran proved a rapid financial success, with global turnover exceeding \$1bn by April 2012. But, as sales soared, concerns grew about the reports of fatal bleeds that were beginning to emerge.

As Deborah Cohen reveals in The BMJ's investigation this week (BMJ 2014;349:g4670, doi:10.1136/bmj.g4670), the company withheld important analyses from the regulators showing that monitoring drug plasma concentrations and adjusting the dose could improve safety. Instead, Boehringer Ingelheim's marketing strategy emphasised the no monitoring message. "No need for regular blood tests to see if your blood-thinning level is in the right range," boasted one of its US advertisements. Company documents revealed in the course of US litigation over dabigatran show how, with proper monitoring, and changing the dose as needed, major bleeds could be reduced by $30-40 \%$ in comparison with well controlled warfarin. But, as Cohen discovered, neither doctors nor regulators have ever been aware of these calculations. Instead, guidelines (including those recently issued by the UK National Institute for Health and Care Excellence (BMJ 2014;348:g3655, doi:10.1136/bmj.g3655)) have recommended the new generation of oral anticoagulants such as dabigatran, "in part because they don't require monitoring," writes Cohen.

In an accompanying Analysis article, Thomas Moore, a senior scientist at the US Institute for Safe Medication Practices, says that reducing bleeding "deserved to be ranked as a patient safety issue of the first order" (BMJ 2014;349:g4517, doi:10.1136/ bmj.g4517). One of the problems, as Rita Redberg and Blake Charlton point out in their editorial, is that dabigatran benefited from FDA programmes to stimulate innovation, "which also contributed to a less robust evaluation of risks and benefits" (BMJ 2014;349:g4681, doi:10.1136/bmj.g4681).

Statins, as Ben Goldacre and Liam Smeeth write in their editorial (BMJ 2014;348:g4745, doi:10.1136/bmj.g4745) to accompany our summary this week of NICE's updated guidance on statins for prevention of cardiovascular disease (BMJ 2014;349:g4356, doi:10.1136/bmj.g4356), are more likely to do good than harm. And yet, they add, "the current data on statins have many avoidable shortcomings. Important questions on comparative efficacy, and efficacy in different risk strata, have never been adequately answered." What is needed for informed choice when offering a preventive drug to potentially large numbers of healthy people, Goldacre and Smeeth say, is better data, from bigger trials, and better risk communication than for conventional treatment. They conclude, "Without such innovation in the use of medical data, we can say only that statins are-broadly speaking - likely to do more good than harm. That is not good enough."

Cite this as: BMJ 2014;349:94793

๑ BMJ Publishing Group Ltd 2014 